\title{
A NEW INTEGRATED MONITORING SYSTEM FOR HELICOPTER EMERGENCY MEDICAL SERVICE
}

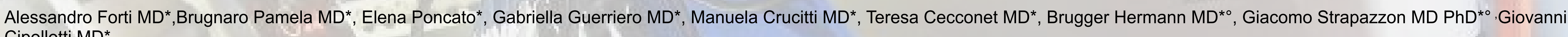
Cipollotti MD*

*Emergency Department ULSS 1 Dolomiti Belluno, Italy; ${ }^{* 0}$ : Institute of Mountain Emergency Medicine, Eurac Research, Bolzano, Italy,

\section{PURPOSE OF THE STUDY:}

A new integrated monitoring system (Zulu Medical System Treviso-Italy) has been tested in a Helicopter Emergency Medical Service setting. This monitoring system can perform a digitization of patient's medical data.

\section{MATERIALS AND METHODS:}

The new integrated monitoring system was used by the Helicopter Emergency Medical Service of Pieve di Cadore (Belluno, Italy) from 10 August 2015 to 16 April 2018

The monitoring system was installed on a fully rugged F110 tablet (Getac Technology Corporation, Taiwan).

Patients vital signs were collected by appropriate Bluetooth devices and a record form, previously written on paper, was filled in by the medical team directly on the tablet. Finally, reports were sent to the emergency department of the hospitals directly from the helicopter before arrival using a certified mail. The system also allows to collect data for statistical analysis.

\section{RESULTS}

Data collected during 1186 missions are reported in table 1.

\section{CONCLUSIONS}

The great advantages of this system is above all not to have sheets of paper. You can also perform free from cables monitoring into a 10 meters' distance, take photographs with geolocation and attach theme to finally report, collect data for an easy quantitative and qualitative analysis.
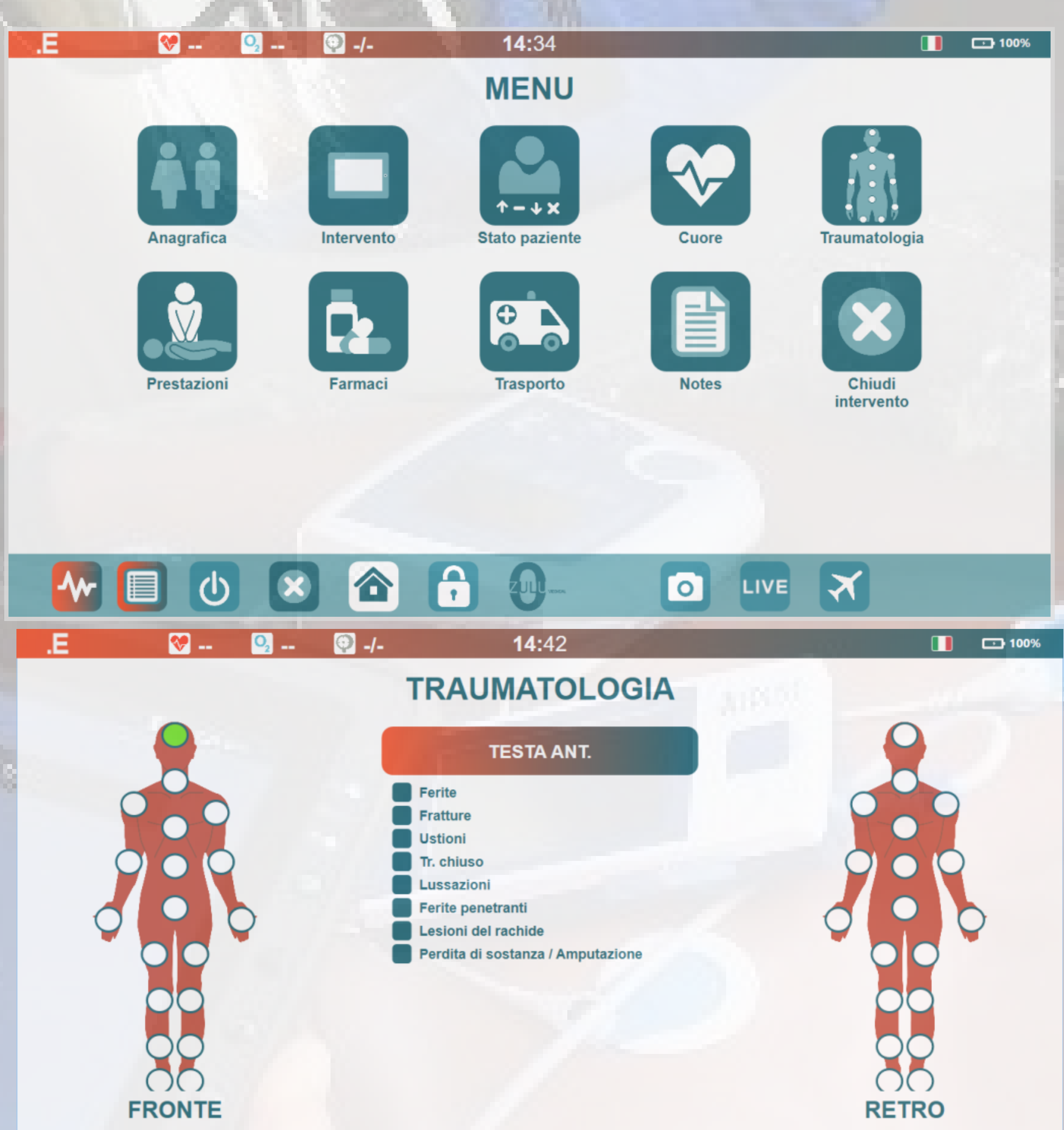

$\sin =$

的田 8000

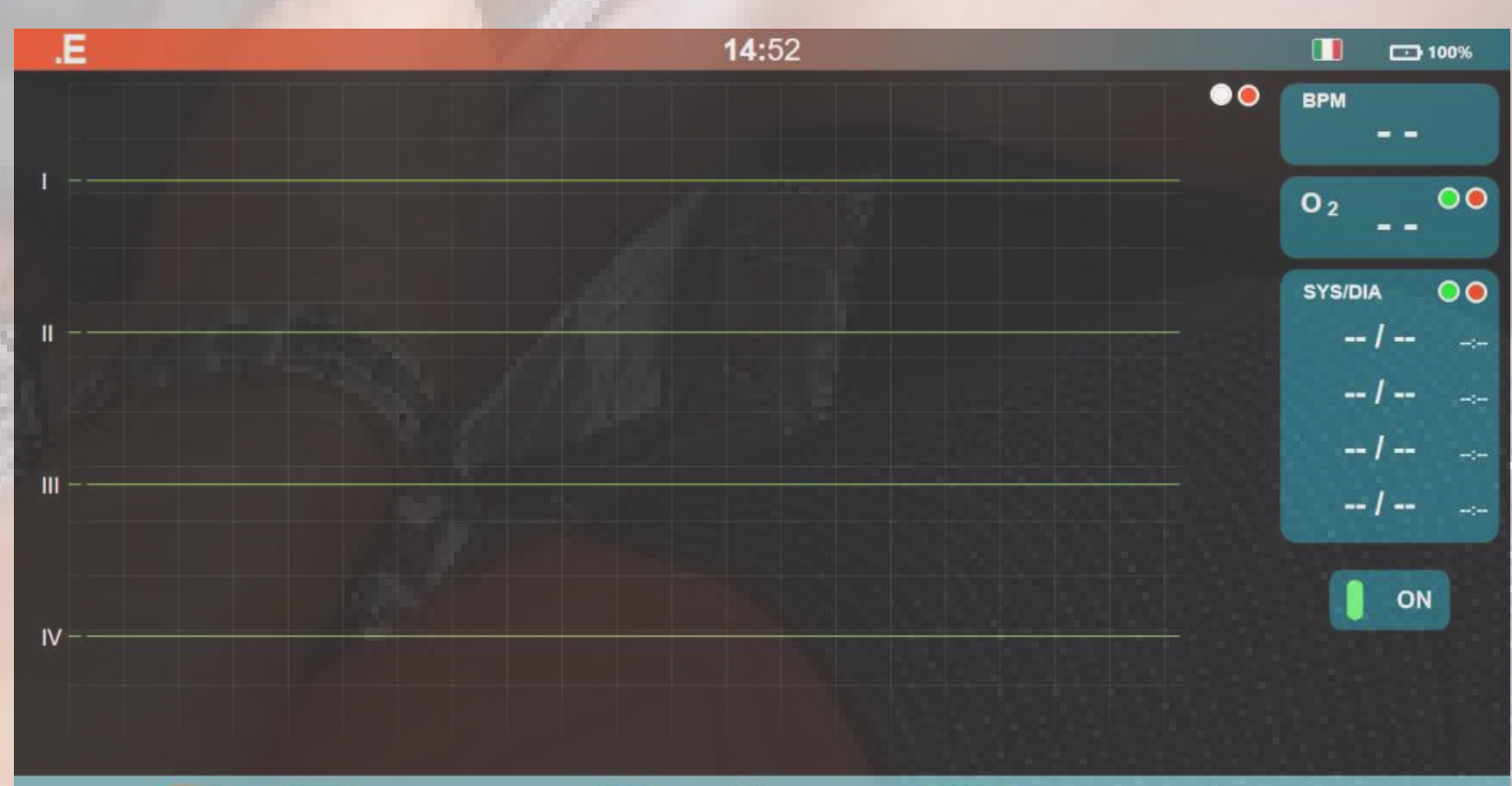

圆 し

(1) 2

X

$\rightarrow$
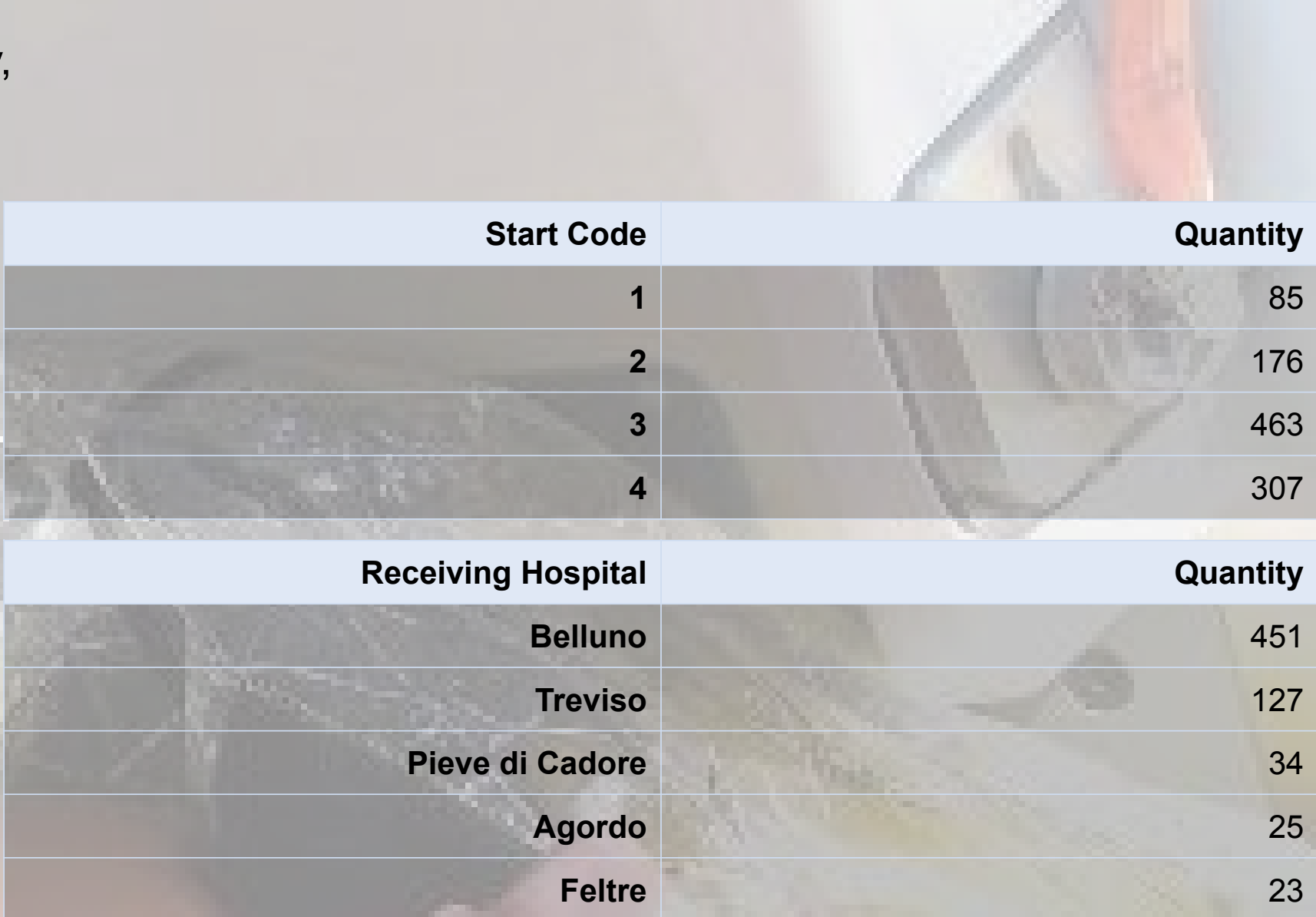

Intervention: immobilization devices Quantity

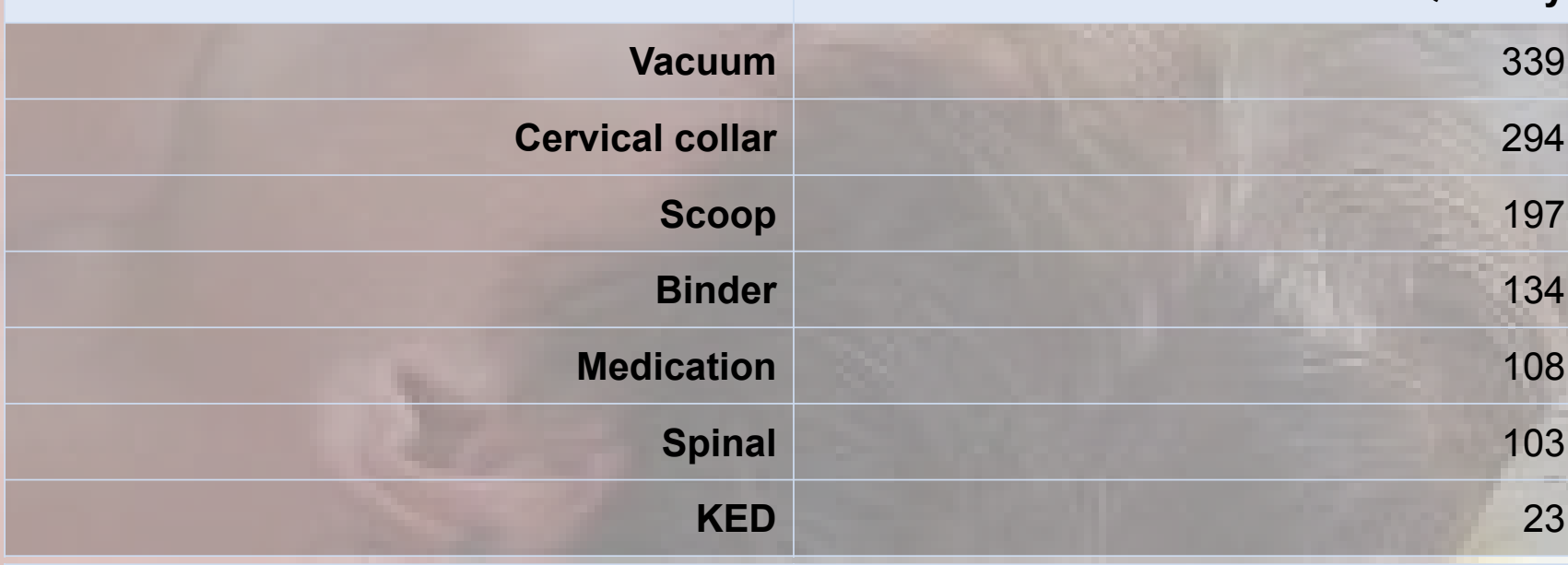

Intervention: Circulation

Peripheral venous access

Nacl solution

Intervention: Breathing

Oral Intubation

Manual ventilation

Mechanical Ventilation

Rinotracheal intubation

Sovraglottic devices
Quantity

Quantity

Monitoring

IperHAEs

CPR

Shock

Intraosseus

Oxygen

Aspiration

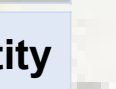

\begin{tabular}{l|l|l|}
21 \\
-19
\end{tabular} 